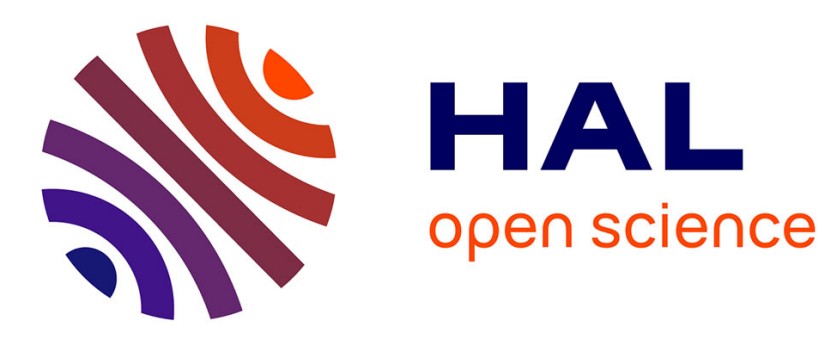

\title{
Spatial science and network science: Review and outcomes of a complex relationship
}

César Ducruet, Laurent Beauguitte

\section{To cite this version:}

César Ducruet, Laurent Beauguitte. Spatial science and network science: Review and outcomes of a complex relationship. Networks and Spatial Economics, 2014, 14 (3-4), pp.297-316. 10.1007/s11067013-9222-6 . halshs-01093664

\section{HAL Id: halshs-01093664 \\ https://shs.hal.science/halshs-01093664}

Submitted on 10 Dec 2014

HAL is a multi-disciplinary open access archive for the deposit and dissemination of scientific research documents, whether they are published or not. The documents may come from teaching and research institutions in France or abroad, or from public or private research centers.
L'archive ouverte pluridisciplinaire HAL, est destinée au dépôt et à la diffusion de documents scientifiques de niveau recherche, publiés ou non, émanant des établissements d'enseignement et de recherche français ou étrangers, des laboratoires publics ou privés. 


\title{
Spatial science and network science: Review and outcomes of a complex relationship
}

\author{
DUCRUET César ${ }^{1}$ \\ French National Centre for Scientific Research (CNRS) \\ UMR 8054 Géographie-Cités, Paris, France \\ Email: cdu@parisgeo.cnrs.fr
}

BEAUGUITTE Laurent

UMR 6266 IDEES, Rouen, France

Email: beauguittelaurent@hotmail.com

Pre-final version of the paper published in

Networks and Spatial Economics, Vol. 14, Issue 3-4, pp. 297-316.

\begin{abstract}
For decades, the spatial approach to network analysis has principally focused on planar and technical networks from a classic graph theory perspective. Reference to models and methods developed by other disciplines on non-planar networks, such as sociology and physics, is recent, limited, and dispersed. Conversely, the physics literature that developed the popular scale-free and small-world models pays an increasing attention to the spatial dimension of networks. Reviewing how complex network research has been integrated into geography and regional science reveals a high heterogeneity among spatial scientists as well as key directions for increasing their role inside multidisciplinary researches on networks.
\end{abstract}

Keywords: complex network, scale-free network, small-world network, geography, regional science, spatial network

\section{Introduction}

A rapid surge of interest in networks in the late 1990s throughout natural and social sciences has witnessed the emergence and diffusion of new concepts and measures. The sudden interest by physicists in network analysis in the late 1990s principally provided models of networks based on two main dimensions: the small-world network (hereafter SWN), based on average distance path and density of neighborhoods (Watts and Strogatz, 1998; Watts, 2003), and the scale-free network (SFN) based on the hierarchy of hubs (Barabási and Albert, 1999). SFN and SWN have quickly spread across various disciplines and scientific fields (Newman et al., 2006). While physicists have increasingly integrated the spatial dimension in their works (Barthélemy, 2010), geographers and regional scientists seem to have so far paid rather limited attention to complex networks research. Far from interpreting this state of affairs as a weakness, this paper proposes a review of existing applications.

This review takes its inspiration from earlier ones by Borgatti et al. (2009) and Crossley (2005, 2008) about sociology as well as Alderson (2008) on operations research and Ducruet and Lugo (2013a) on transport networks and systems of cities. We examine how the most popular theoretical models of networks proposed by physicists (i.e. scale-free and smallworld) have been integrated in the works of geographers and regional scientists, assess what

$1 \quad$ Author for correspondence 
have been the benefits and speculate whether such concepts are likely to increase their influence in further works. In a first attempt to evaluate the benefits of these approaches in geography, Rozenblat and Mélançon (2007) noticed that "this type of empirical approach combining a conceptual approach of 'small world theory' and dedicated tools has not been developed in geography". Although more recent contributions from regional science do support the necessity for further bridging "spatial economic science" with "network science" (Reggiani, 2011), little has been done in classifying existing applications of complex network theory in geographical research.

The structure of the paper is as follows. The first section briefly recalls the evolution of network analysis in geography and regional science. Secondly, we provide a short review on the emergence of complex network research, followed by a more scrutinizing look at the influence of space in the works of physicists. The third section examines how geographers and regional scientists have used these measures and concepts in their works either independently or through collaborations with physicists and computer scientists. In conclusion, we discuss differences in respective approaches and potential paths for further research.

\section{Network analysis in geography and regional science}

Without being exhaustive, this review will consider the evolution of network analysis in geography as a whole in the last few decades before addressing current issues and challenges. Since the quantitative revolution of the 1960s, network analysis in geography has remained rather simple. Network analysis is mainly used by transport geographers who apply graph theory to planar - a network is called planar when its edges (or lines) do not cross each other - and technical networks (e.g. roads and railways, see Kansky, 1963; Haggett and Chorley, 1969; Dupuy, 1988; Mathis, 2003). The wider paradigm shift from structural to behavioral approaches is seen by Waters (2006) as a main cause for the declining interest in spatial analysis as a whole, where network analysis 'remained somewhat of a backwater' notably due to limited data availability and computational power (Xie and Levinson, 2009) and despite improvements provided by Geographical Information Systems (GIS) since the 1980s. Following an early methodological transfer from mathematics and notably from French mathematician Berge (Kansky, 1963: 10-13), several measures kept being used by geographers under different names than in other disciplines, thus reflecting upon limited interdisciplinary discussions (e.g. $\alpha, \beta$, and $\gamma$ indices). According to Gorman et al. (2004), few scholars have improved existing connectivity indices (i.e. indices that measure the quality of connection between nodes), because such progress remained hindered by a lack of knowledge about the history and development of network analysis in geography and in other disciplines (Waters, 2006). The review of indices was recently updated by Melançon and Rozenblat (2013) in their effort for further bridging computer sciences and geography.

This situation also applies to software packages dedicated to network analysis where graph non planarity - here edges can cross each other - is considered as a norm, and the aforementioned indices are generally unknown ${ }^{2}$. Indeed, such classic graph theory measures have been criticized due to their outdated character (Waters, 2006) and lack of robustness for comparing different network topologies (Béguin and Thomas, 1997; Kurant and Thiran,

\footnotetext{
2 Without being exhaustive, the following software packages do not know the alpha, beta, etc. indices: Ucinet, Pajek, Tulip, Gephi, igraph (R package), statnet (R package), and blockmodeling (R package).
} 
2006), but they are still used nowadays to describe the evolution of one given network (Scott et al., 2005; Bretagnolle, 2009; Xie and Levinson, 2007, 2009; Wang et al., 2009). Such measures were also successfully applied by geographers to many planar networks in early works such as the density of networks all over the world (Garrison, 1960), the growth of the French railway network (Dancoisne, 1984), the connectivity of the Parisian subway network (Ciceri et al., 1977), and the hierarchical structure of river networks (see also Haggett and Chorley, 1969). Other contributions about the modeling of transport network evolution (Taaffe et al., 1963) had great influence on port geography research for instance $(\mathrm{Ng}$ and Ducruet, forthcoming). This characterization has changed in the 1990s when geographers started to represent and analyze non-planar networks, thereby stepping out of 'classic' graph theory and thus needing more advanced tools to represent and analyze such networks. Studies of the European urban system progressively integrated a network dimension with the works of Cattan (1995) on airlines and railways, and Rozenblat and Pumain (1993) on multinational firms, thereby opening new ways considering systems of cities (see also Batty, 2008).

Relations between geographers, spatial scientists, and Social Network Analysts (SNA) remain limited although sociologists developed their tools from the 1930s while focusing exclusively on non-planar graphs (Wasserman and Faust, 1994). It is true however that SNA remained marginal until the late 1960s throughout sociology (Freeman, 2004: 83-86), while the geographical tradition regarding network analysis remained rather stable, thus contributing to limited dialogues between them. The famous experience of Stanley Milgram (1967) had very limited diffusion in geography except from a paper by Stoneham (1977). Very briefly, the aim of this experience was to investigate the number of relations needed to connect randomly chosen individuals in the United States: participants from a small town in Nebraska were asked to send a letter to a person they called by name, the objective being to reach a target on the East coast. If many participants gave up, letters reaching their goal needed in average 5 intermediaries. This quickly became a popular expression: six degrees of separation (i.e. six persons only) are needed to connect any couple of persons in the world. Indeed, Social Network Analysis has been little noticed by geographers until recently (Grabher, 2006; Ter Wal and Boschma, 2009; Radil et al., 2010) as sociologists increasingly consider the influence of space in their works. The role of spatial interaction in a social network was for instance tested by Illengerger et al. (2013) showing that spatial proximity only affected the spatial structure of the network but not its topology.

In addition, most studies of transportation networks in social sciences do not refer to complex networks but rather use other methodologies derived from graph theory (see a review by Ducruet and Lugo, 2013b), such as global indices and single linkage analysis to map nodal regions (Cattan, 1995a; Grubesic et al., 2008). Notably, the wide field of spatial analysis barely mentions complex networks as it rather puts strong emphasis on econometrics, GIS-T (Geographical Information Systems for Transportation), autocorrelation, optimization, modelling and accessibility issues traditionally in a transportation network (Miller, 1999; Thomas, 2002; Reggiani et al., 2011a). Spatial analysis has developed its own approaches based on some seminal works on spatial interaction principles but without explicitly mentioning networks per se (Tobler, 1970). According to Ducruet and Lugo (2013a), this also applies to the New Economic Geography (NEG) where flows, networks, and distances are not introduced per se in existing models, where, for instance, cities and regions remain equally spaced across an abstract space. In parallel to those developments, the concept of network in geography has witnessed increasing importance in many discussions on global production networks, commodity, value, and supply chains, corporate networks, but from the perspective 
of actors, strategies, and territorial contexts rather than analyzing network topologies per se (Jacobs et al., 2010).

\section{Complex networks and space}

\subsection{General properties}

The concepts of 'small-world network' and 'scale-free network' were first proposed by the respective works of Watts and Strogatz (1998) and Barabási and Albert (1999). Their goal was to define models of network organization differing from random networks (Erdös and Rényi, 1959). In this last model, links between nodes are randomly distributed, thereby providing a normal degree distribution - the node degree being the number of links adjacent to it. As mentioned above in the case of geography, most research in graph theory and network analysis in general has long been focused primarily on regular and random networks - a network is called $k$-regular when each node has the same degree equal to $\mathrm{k}$. If random networks were important for development of network analysis, they had no impact on geographical studies.

SWNs exhibit a small average path length between pairs of nodes - few links separate node pairs on average - and a high local clustering coefficient - also called transitivity by sociologists: probability for nodes that their adjacent neighbours are linked. The latter dimension comes from the popular expression by which my friends are also friends or, in other words, if $\mathrm{A}$ is connected with $\mathrm{B}$ and $\mathrm{C}$, then the probability for $\mathrm{B}$ and $\mathrm{C}$ to be also connected is high. One of the main drawbacks of this definition is its extensiveness: if we except tree graph (graph without cycle: impossibility to find a way back to the starting node), nearly all graphs issued from empirical studies are SW, even technical ones (one of the current example regarding physicists literature is the US power grid). SFNs contain few large degree nodes and a majority of small degree nodes, resulting in a strong hierarchical structure. Plotting the node degree distribution reveals a power-law structure. This structure gets strong similarities with power-law characteristics previously discovered in various fields, including urban geography. It appeared however as something innovative in the network field as previous studied network presented rather a Gaussian degree distribution.

SWNs and SFNs have in common several features (see Newman, 2010 for a useful synthesis). They are more efficient in terms of ease of circulation within the network, which can be measured by the average shortest path length, as those networks allow limiting the number of stops between two nodes on average. In addition, they include many hubs (bridge nodes) and isthmuses (crucial links) between densely and tightly connected communities or 'clusters', based on the idea of cliques (Wasserman and Faust, 1994). These hubs and isthmuses present generally a high level of betweenness centrality - many paths in the network have to pass through these nodes (for a mathematical definition, see Wasserman and Faust, 1994). But such networks also have some important differences. SFNs are less 'clustered' than SWNs due to the stronger influence of large degree nodes, which lowers the clustering coefficient. SFNs seem more efficient as the presence of hubs provides optimal circulation and less friction. SWNs are denser than SFNs because removing few hubs would result in the identification of communities. Yet, large degree nodes tend to form cliques in SFNs and this can be measured by the rich-club coefficient (density of links measured among nodes with high degree). 
Usually, the structure of SFNs is described by plotting node frequency over degree distribution in a log-log diagram. The slope (exponent) of the power-law line gives an indication whether the network is scale-free, i.e. when values of the exponent are over 1 or even 2 (this threshold not being clearly defined). The existence of scale-free networks is explained by a dynamic process called preferential attachment: when new nodes are added to the network, they primarily connect the already large nodes, thereby reinforcing the hierarchical structure (Internet is a nice example of this phenomenon: a new website on any subject primarily creates links towards most popular websites in the same field). Such properties inherent to SWNs and SFNs were in fact already expressed in a number of related concepts and growth models, as underlined by the recent review provided by Zaidi (2011) on complex networks. Firstly, the power-law structure and the preferential attachment process were already described by the Yule (1925) process, by the Gibrat (1931) law (growth is proportional to size), by Jackson (1935) with the 'rich get richer' idea, by Zipf (1949) on the rank-size rule, by Price $(1965,1976)$ about the cumulative advantage process observed in citation networks, and by Merton (1968) about inequality in credit attribution among researchers. Secondly, the works of Milgram (1967) as well as Travers and Milgram (1969) were in fact the first to demonstrate the topological proximity among distant individuals and to label it as 'small-world phenomenon'. Earlier, Simmel and Wolff (1950) first proposed the concept of triad to depict mutual acquaintances in a social network, and how they are likely to evolve. In geography, Gibrat's model was applied to systems of cities (Robson, 1973; Pumain, 1982) as well as to urban economics (Gabaix and Ioannides, 2004) to examine the evolution of urban growth through city size distributions.

In fact, the merit of recent works by Watts and Strogatz (1998) and Barabási and Albert (1999) has been to reincorporate such ideas into clearly defined models of network structure and evolution, together with associated measures and methods directly usable for empirical research. Several measures have been proposed to highlight the properties of networks, such as the aforementioned power-law coefficient, transitivity (clustering coefficient), and average shortest path length, together with assortativity (degree-degree correlation). In the end, physicists have mostly relied on existing measures, but they have also modified and improved them in order to take the weights into account, which has long remained a drawback of graph theory (Opsalh and Panzarasa, 2009). Weighting, for instance, the clustering coefficient and the rich-club coefficient provides very useful answers to the question whether larger nodes are more strongly interconnected with each other than with smaller nodes, i.e. whether hubs form cliques in the graph. If weight is taken into account, directionality is barely considered by physicists, even when links are obviously directed (cf. Barábasi's studies of the Internet structure). A number of measures, however, are simply revisited without referring to their background in graph theory and geography. This is the case of the "rich-club coefficient" and the "greedy triangulation" being respective applications of the Gamma and Alpha indices proposed by Kansky (1963) - the first one is the ratio between the actual and the possible number of edges in a graph, the second one is the ratio between the actual and the possible number of cycles in a graph.

A recent but promising trend is the growing interest of physicists in so-called 'spatial networks'. Before examining what geographers did with these two models and the associated measures, it appears necessary to look at this recent spatial perspective proposed by physicists.

\subsection{The spatial dimension}


A large number of research papers seeking small-world and scale-free properties in networks of all kinds has been produced in the last two decades at exponential pace, thus making reviewing the field exhaustively difficult. Given the similarity of methods and measures from one case study to the other, we review a number of works principally focusing on the spatial dimension of SFNs and SWNs.

Natural scientists have themselves criticized mainstream research on networks due to the noninclusion of the spatial, social or economic dimension in general measures and models (Watts, 2003: p.29 and 67; Evans, 2010). In this respect, similar criticism emerged about the ActorNetwork Theory (ANT) originating from sociology and often neglecting the importance of space in the position of actors and its influence on their relations (Bosco, 2006). The material and geographical embedding of some networks appears only implicitly in the small-world model, while it is absent of the scale-free model ${ }^{3}$. In addition, Watts (1999) found that preferential attachment often occurs over shorter distances. A distinct category of spatial networks ${ }^{4}$ thus emerged in an explicit way in the physics literature, which actually applies to a majority of real-world networks in contrast with theoretical models of networks (Gastner and Newman, 2004) and non-spatial networks (e.g. social network, world wide web). The geographical dimension of social networks has, however, been discussed regularly as shown in an extensive review published by psychologists in a physics journal (Wong et al., 2006). They demonstrate the importance of distance in random graphs by means of Monte Carlo simulation methods, where main results underline a decreasing probability for density and community formation as distance increases. Similar results were found on the basis of social distance (Boguna et al., 2004).

Yet, many works on spatial networks do not specifically measure their spatial dimension, as they only look at their topological dimension as in the case of maritime networks ( $\mathrm{Hu}$ and Zhu, 2009) and commuter flows (De Montis et al., 2010; Reggiani et al., 2011b; Caschili and De Montis, 2013) where distance parameters are not included. Spatial networks are defined by physicists (Barthélemy, 2010) through some fundamental properties: physical embedding and interaction range. Physical embedding refers to nodes and/or links being grounded in a physical (Euclidian) space, which in turn constrains the multiplication of links and orientates the layout of the network, with the crucial importance of borders. Interaction range means that distance metrics (and related costs) play a central role in the emergence, distribution, and weight of links, since spatial proximity is one dominant factor favouring short-range versus long-range interaction.

Several scholars have thus explored the influence of spatial structure on network topology in static and dynamics ways (Waters, 2006). Among the earliest attempts to validate this idea, Barthélemy (2003 and 2010) showed that spatial networks in general exhibit higher clustering coefficients than non-spatial networks due to the importance of proximity in node connectivity (see also Kaiser and Hilgetag, 2004). Further results were provided by Barrat et al. (2005) based on the case of air transport highlighting several other properties of spatial networks such as: fewer global hubs and more regional hubs, higher disassortativity as the network grows (nodes having a high degree tend to connect preferentially with nodes having a

3 Barabási (2002) recognized that cities connecting thousands of highways simply do not exist, thereby recognizing implicitly physical constraints to network growth.

4 Spatial networks are also coined geographical networks, technological networks, infrastructure networks, ad-hoc networks, or physical networks in the literature. 
low degree), higher correlation between degree and betweenness, increased influence of the barycentre on betweenness values, and increased cliquishness. However, the fundamental difference between planar and non-planar networks is not always considered by physicists. For instance, planar spatial networks are more physically constrained and thus are more assortative, with a higher probability to contain a giant component (i.e. connected subgraph including a majority of the nodes), while non-planar spatial networks are more likely to exhibit scale-free properties (Bullock et al., 2010). Spatial or geographical networks are also less vulnerable to random attacks on hubs while adding more local links further eliminates such vulnerability (Hayashi, 2006; Gosak et al., 2011). Lambiotte et al. (2008) have argued, however, that although spatial networks validate the gravity model, they are also made of crucial long-distance links deforming the predictions. A study of the evolution of the Swiss road and railway networks (Erath et al., 2009) also discussed the limited accuracy of complex network measures for studying spatial, planar networks, thereby complementing them with local network density measures.

Methods used for testing the influence of spatial embedding range from the inclusion of simple distance parameters to the simulation and modelling of complex networks embedded in two-dimensional space (for an early review see Boccaletti et al., 2006, pp. 205-212), based on the hypothesis that connectivity is a function of distance (Barnett et al., 2007). Notably, Crucitti et al. (2006) take into account physical distance in their calculation of node centrality, arguing that their results may be more useful to urban planning and design. In the same vein, Cardillo et al. (2010) include metric distance in their analysis of urban streets, notably comparing observed and optimal efficiency, while Gattuso and Miriello (2005) reviewed the possible measures to analyze metro networks topologically and geographically. Andersson et al. (2005) tested the influence of various parameters, such as transport costs, on the emergence of power-laws in land values. Other works adopted a node redundancy approach to study the influence of spatial structure on cascading failures (Huang et al., 2006), arguing that stronger geographical constraints foster the 'reservoir effect' of hubs (i.e. redistribution of traffic from smaller nodes to larger nodes situated in close proximity), while such spatial networks face higher risks of becoming disconnected due to their higher density. Expert et al. (2011) adapted a modularity function - modularity being a measure of clustering quality - to spatial networks in order to better understand the influence of the spatial factor on network structure, with an application to Belgian mobile phone communication flows between individuals. They particularly revealed the regionalization of the network based on an extension of the modularity algorithm. When it comes to the simultaneous analysis of several spatial networks, Parshani et al. (2010) notably demonstrated that location matters in the inter-similarity of networks, based on ports and airports' geographical coordinates. One last point must be made: the planarity of graphs has never been a great subject of concern except in geography, the most obvious example being the manual from Haggett and Chorley where non-planar graphs are mentioned twice only (1969: p.4 and 7). More recently, efforts have been made to model the growth of urban streets to reveal historical paths ( $\mathrm{Ba}$ rthélemy and Flammini, 2009; Strano et al., 2012).

If physicists, computer scientists, but also other disciplines (see Davis et al., 2003; Fleming et al., 2007), integrate more and more space in their network studies, how have geographers integrated these new models and measures? The next section proposes a review of recent geographical researches on networks. Regional science being a quite autonomous field nowadays in geographical science, we will mention some authors and papers but without pretending to be exhaustive. 


\section{Complex networks in geographical research}

\subsection{Classification of existing studies}

A review of recent applications of scale-free and small-world networks by geographers and regional scientists provides a somewhat balanced picture of the varied outcomes. Often through cross-disciplinary collaborations ${ }^{5}$, scholars proposed to refine and test further some methods and measures, based on their knowledge of the thematic field and their higher interest for local level issues than for global level structure. Because the concepts of spatial network and complexity do appear in several works without explicit reference to complex networks, we limited the review to those explicitly mentioning and/or using concepts and methods from complex network theory. Those are classified among six main research areas, which also constitute future fields of investigation of further works.

\section{Local determinants of centrality}

The easiest way to integrate complex network methods has been to apply series of new measures to various graphs. One dominant outcome of geographical research is to underline significant statistical correlations between different centrality measures (i.e. degree, betweenness, and closeness - average distance, measured in number of links, between a node and all the other nodes in a network) of cities in Internet and airline networks with local/urban socio-economic data such as population, and gross regional domestic product (GRDP) (Wang et al., 2011; Choi et al., 2006), thereby confirming the importance of territorial aspects. Most of such approaches have consisted in providing new rankings of cities as in the works of the Globalization and World Cities (GaWC) research group, but often without a direct engagement with existing network analytical methods. Affinities between centrality and local development was also verified through cross-disciplinary work including sociology using more advanced tools, such as Eagle et al. (2010) demonstrating the strong interdependency between the diversity of connections and the economic well-being of localities in the UK communication network. Other works also demonstrated inadequacies between network topologies and local development when looking at knowledge networks across urban agglomerations such as co-authorships on a world level (Matthiessen et al., 2006) and in China (Liefner and Hennemann, 2011). In addition, Ducruet et al. (2011a) compared the betweenness centrality of cities in air and sea flows separately and jointly, revealing the importance of the regional setting versus general laws by which more diversified cities would always dominate more specialized cities. At the intra-city level, street centrality was found to have strong affinities with retail and service concentrations in Bologna (Porta et al., 2009) and Barcelona (Produit et al., 2010; Porta et al., 2012).

\section{The role of distance}

\footnotetext{
5 See for instance the SPANGEO I project (Spatial Networks in Geography) based on active collaboration between geographers and computer scientists around the TULIP software (http://s4.csregistry.org/SpanGeo). It is currently followed up through the SPANGEO II project (http://www.unil.ch/igul/page82579.html), with more emphasis on simulation methods. The FMR Research Group on networks organizes a yearly seminar welcoming specialists of networks as well as young scholars from $\begin{array}{lllll}\text { all academic } & \text { disciplines } & \text { since } & 2010 & \text { (http://halshs.archives- }\end{array}$
} ouvertes.fr/view_by_stamp.php?label=FMR\&action_todo=home\&langue=en) 
Surprisingly, distance parameters are barely introduced by geographers in their study of networks. This stems from the belief and implicit claim by geographers that space always matters: they therefore do not seek to prove this assumption but rather look at how other dimensions (social, political, historical) are reflected across space. It was found, however, that seaports with larger degree connect over longer kilometric distances on average based on worldwide inter-port maritime links, based on the average length of the longest links at each degree value (Ducruet and Zaidi, 2012). While the shortest maritime links concentrate the highest proportion of all global shipping flows (Ducruet and Notteboom, 2012), the average and maximum kilometric distances through which ports connect each other have a strong influence on port throughputs (Ducruet et al., 2011b). In the same vein but based on multiple commodity flows, Ducruet (2013a) demonstrated the strong influence of physical distance on the diversity of maritime traffics among ports of the world: more diversified ports connect over longer distances on average, but more diversified links are shorter because the probability of carrying various sorts of goods decreases as distance increases. When studying the Indianapolis road network, Gleyze (2007) proposed to distinguish among networks effects and spatial effects in the measurement of betweenness centrality and eccentricity (node tendency to be apart from the whole network), so as to reveal the influence of friction on centrality measures, just like, more recently, in the work of Vitali and Battiston (2011) on European firms but without referring to same literatures. Jiang and Claramunt (2004) offered a very original approach to urban streets by considering streets as nodes and crossroads as links in their analysis of small-world dimensions and centralities, in the tradition of the space syntax approach to networks (see Hillier and Hanson, 1984) also developed by Porta et al. (2006) in geography.

\section{Complementary methods}

A series of studies have complemented a complex network approach by other methods in regional science and sociology (SNA). For instance, Patuelli et al. (2007) combined complex networks and Spatial Interaction Models (SIM), and Gorman and Kulkarni (2004) applied SNA methods (e.g. structural equivalence) in their analysis of Internet backbone networks in the US. Gorman et al. (2007) also compared the results obtained from spatial interaction methods (i.e. the gravity model) and complex networks methods about the road network and commuting flows structure in Germany, concluding that such methods are well complementary to each other. In the same vein, Ducruet et al. (2011a) measured the scale-free dimension of the network and applied a Multiple Regression Quadratic Assignment Procedure (QAP) to reveal the correlation between network topologies on different levels of node aggregation. This application on air and sea global networks notably contributed to the fastgrowing research field of coupled infrastructure networks developed in recent years (see Vespignani, 2010). Andersson et al. (2006) discussed the benefits of using complex networks in conjunction with spatial interaction models and multiplicative growth models in the analysis of urban growth, while Schintler et al. (2007) proposed to link raster-based Geographic Information Systems (GIS), graph theory, and complex networks theory to analyze the road and railway networks of Florida. Although the work of Barber et al. (2011) on the identification of communities within the European network of research and development collaboration shows more affinity with Social Network Analysis, it also used the modularity algorithm proposed by physics.

Clusters, communities, regions 
Fourth, geographers have been particularly interested in the multi-level organization of networks. This has led to the refinement of clustering methods when studying the worldwide airline network of intercity passenger flows based on strength clustering (Amiel et al., 2005; Rozenblat et al., 2013) or the Atlantic liner shipping network looking at the correspondence between spatial proximity among seaports and their belonging to same clusters based on the bisecting k-means method (Ducruet et al., 2010). Another example is the analysis by Rozenblat (2010) of the locational logics of multinational firms led both within and among cities. In order to propose new delineations of urban metropolitan areas, Tissandier et al. (2013) also applied the strength clustering method to commuter flows in France, while Drevelle (2013) applied blockmodeling to the graph of commuter flows in the Montpellier urban area to detect the emergence of secondary poles in the suburbs. The analysis of mobile phone communication networks rightfully demonstrated the importance of geographic proximity in the emergence of communities, notwithstanding the influence of borders (Blondel et al., 2010), thereby echoing former studies of this kind based on simpler techniques (Nystuen and Dacey, 1961; Cattan, 1995). Other approaches have clustered and mapped vehicle trajectories so as to reveal traffic regions in Athens (Guo et al., 2010). It is very surprising that this research direction has the lowest number of works, given the traditional endeavor by geographers to reveal regional structures. Yet, the role of physical distance in the formation of clusters and regions remains indirectly tested, except by Gleyze (2013) discussing methods of topological clustering on spatial networks.

\section{Interdependent networks}

Despite the lack of mathematical formalization of multigraphs and multiplex graphs (i.e. graph where several types of links exist between nodes), several works have recently focused on networks characterized by multiple relations among the nodes, notably in physics (Buldyrev et al., 2010; Parshani et al., 2010; Rosato et al., 2008; Vespignani, 2010). Some of them employ statistical measures on time series to study the co-evolution of various nodes and links over time (Bogart, 2009) while others applied more conventional graph theoretic methods to the combination of various links among French cities to reveal regional urban systems (Berroir et al., 2012) as well as social network analysis methods such as blockmodeling (i.e. clustering method based on directionality) to trade and diplomatic relations among world countries to reveal the emergence of a European entity (Beauguitte, 2010). While geographers and regional scientists clearly recognized the need to envisage the simultaneity of multiple relations among nodes (Zhang et al., 2005), they provided efforts mostly at the local level in order to evaluate the specialization level of nodes in multiple networks. Several studies have addressed the conceptual and methodological challenges brought by the analysis of multiple networks in various contexts, such as airlines and Internet networks (Devriendt et al., 2010; Tranos, 2011), airlines and corporate networks (Liu et al., 2013). Another example is Ducruet et al. (2011a) who compared the betweenness centrality of cities in the combined global network of air and sea flows with their centrality in each single network. They also applied a single linkage analysis to the coupled network in order to demonstrate the influence of the regional context by which dominant European cities remain highly specialized (i.e. being central in either air or sea flows) while in the rest of the world, diversified cities (i.e. having a balanced position in air and sea flows) tend to polarize other cities. In such works as well as for physicists, the geographical criteria are fundamental to study the interdependence of networks based on their physical correspondence through spatially embedded nodes. 


\section{Evolution and dynamics of networks}

Geographers have paid particular attention to the evolution of networks, in more concrete ways than physicists due to the use of real-world empirical time-series data. Notably, Vinciguerra et al. (2010) tested the influence of geographical distance and country borders on the evolution of the European Internet backbone network, with reference to the BarabásiAlbert model of preferential attachment. The evolution of inter-city scientific research partnerships was studied by Comin (2009) to reveal the reinforced position of larger cities in the network over time despite the multiplication of links towards second-tier cities. The diachronic dimension is indeed much neglected by physicists when it comes to actual data rather than simulation models. This research direction remains, however, little explored by geographers as most of their contributions remain highly static. Most of the time, one same network is mapped and/or visualized at different time periods without questioning the underlying mechanisms of the observed dynamics. Simulation experiments are often applied to a set of locations such as cities but among which the links remain implicit (Bretagnolle and Pumain, 2010). Another recent example, is however, provided by Lugo (2013) who modeled a system of cities connected by road as a planar spatial network and proposed a preferential attachment process based on the size of cities and infrastructure data. Other efforts are being made to map and analyze the evolution of the global maritime network of merchant vessel flows since the 18th century in relation with globalization, urbanization and regionalization processes (Ducruet, 2013b).

\subsection{Collaboration patterns}

So as to better situate geographers in the wider research community on complex networks, Figure 1 proposes an overview of collaborations in the form of a graph where nodes are article authors and disciplines have different colours. This sample of articles comprises the aforementioned works on complex networks including at least one geographer and/or regional scientist besides other scholars belonging to other social sciences (e.g. sociology, history, psychology, etc.), physics, computer science, and engineering. One clearly observes distinct combinations of scientific expertise in the integration between complex network methods and geographical issues, as well as a number of connected components with no links between them. Physicists were included in only four research groups containing geographers, and three of those groups are the largest in terms of the number of authors. This suggests the necessity for geographers to have attained sufficient critical mass before attracting people from natural sciences. Except for the group led by Gorman that does not include physicists, the four aforementioned groups contain at least one scholar from other social sciences as well as from computer science and engineering. Innovation in geography thus necessitated wide collaborations across different fields. Other groups without physicists and/or computer scientists remain smaller in size and bound to a single team specialized in one topic. In addition, the role of geographers differs among the groups: it can be relatively peripheral (i.e. mobile phone networks, urban streets) or very central (i.e. air and sea networks, urban growth). In the two latter cases, geographers have thus been either followers/external experts or leaders/launchers of related research projects. Among the two large groups where geographers dominate by their number, one remains specialized in economics while the other includes physicists and computer scientists. Although such groups might in reality not refer to formal research teams, their configuration, overall, points at a rare central role of geographers, i.e. in only one of the groups, the one specialized in air and sea networks and cities. All 
groups remain rather locked-in and no scholar yet acts as bridge among those groups, should it be from natural or social sciences.

\section{[Insert Figure 1 about here]}

Based on this review, one concludes to a very fragmented body of research when it comes to integrate geographical research with complex networks research. The linking of the unconnected research communities that appeared in Figure 1 is not likely to happen given the scattered approaches, respective specializations as well as research focus. Contrary to what happened in the 1960s when a small group of American geographers led the innovation by importing graph theory into geography, the current picture remains rather disorganized and made of peripheral and episodic contributions to the field.

\section{Discussion and conclusion}

This paper has reviewed a number of classic and novel approaches to network analysis by both natural and social sciences around the concept of space. The rather limited and fragmented dimension of recent works referring to complex networks in geography and regional science is one main conclusion which may have various causes. On the one hand, the shift away from structural approaches in the 1970s can be seen as one of them. The concept of network has gained unprecedented importance in geographical thought, but this has occurred from a conceptual rather than a methodological perspective, with a strong emphasis on actors, scales, innovation, and power relations across space (Pflieger and Rozenblat, 2010). Yet, this cannot explain why quantitative geographers have not been faster in adopting SFNs and SWNs, as they did in the 1960s when integrating graph theory. One major difference with the context of the 1960s remains the difficulty for geographers to access and handle large-scale datasets and thus, to master related methods of analysis in the fields of data mining and statistics. On the other hand, one likely reason is the limited innovation brought by complex networks research to geography, the power law distribution being for example an obvious non-discovery (Reggiani and Vinciguerra, 2011), but again, no geographer has clearly expressed such critique in a formal review of the field as it was done by the aforementioned sociologists. More likely are direct applications of network measures and indices without any reference to wider reflections on complexity theory, although the bridge between complexity, geography, and spatial economics has been firmly made in both conceptual and empirical ways (Lane et al., 2009). Further progress in the cross-fertilization between network science and spatial science should then be both conceptual and practical: what are we measuring? What do the results mean? What do we learn new, to answer which question(s)?

Many tools exist nowadays (e.g., GIS, R packages) which can provide a valuable help to test measures and methods on networks. Geographers focusing on migration, economy, political geography, without mentioning transport geography, could surely examine further the relevance of these innovations. Questioning their relevance cannot be done without testing these measures. In addition, geographers have the opportunity to improve the integration of space (and time) in network research, which has many concrete applications and is being adopted by decision-makers as a relevant approach to their problems. The works of physicists indeed still has some weaknesses despite their abundant (and sometimes redundant) production: absence of critical discussion on data quality and relevance, limited knowledge on the specific study field, problems of graphical semiotics in cartographic expression, and shortage of results' interpretation and policy implications. 
These weaknesses could also be considered as advantages: being less constrained by data viability or conceptual discussions, results are produced faster and with less production lag. Such drawbacks, combined with the trend to rediscover well-known measures by giving them a new name (the most obvious being the transitivity renamed global clustering coefficient), still cannot fully erode the potential benefits of SFN and SWN models. In our opinion, further research in geography may insist on the necessity to analyze networks as elements of wider territorial structures. Can we identify socio-economic invariants in the hierarchy of places and in the emergence of dense communities in the network? Are there determinants of network evolution beyond the sole role of costs and Euclidian distances? Investigation of such questions would prove fruitful, in particular, for the further study on the internal (meso) organization of networks, with regard to the emergence of clusters/communities (of places, firms, actors, etc.). Distance and other kinds of spatial frictions can be better integrated in the graph partitioning and clustering techniques, but no software proposes yet an integrated package combining spatial statistics, GIS, graph visualization, and network analysis "all in one". The extent to which nodes in a cluster are geographic neighbours and/or share similar socio-economic profiles has been poorly studied. The importance of distance is thus often taken for granted by geographers, while physicists directly measure its role in networks. Dynamic clustering techniques could also be further used by geographers in their study of regionalization and globalization processes. In other words, the added value of geographers in (complex) network analysis is their core interest for spatial matters, while most networks are actually spatially and territorially embedded. Further engagement in the visualisation of spatial networks through active collaboration between geographers and computer scientists has already started, however (see Lambert et al., 2013). Perhaps, after a phase of rather passive application of existing methods, geographers should go further in the conceptualization and analysis of networks, by collaborating further with other disciplines and scientific fields.

\section{Acknowledgements}

The research leading to these results has received funding from the European Research Council under the European Union's Seventh Framework Programme (FP/2007-2013) / ERC Grant Agreement n. [313847] "World Seastems".

\section{References}

Alderson DL (2008) Catching the "network science" bug: Insight and opportunity for the operations researcher. Operations Research, 56(5): 1047-1065.

Amiel M, Rozenblat C and Mélançon G (2005) Réseaux multi-niveaux : l'exemple des échanges aériens mondiaux de passagers. M@ppemonde, 3: http://mappemonde.mgm.fr/num7/articles/art05302.html

Andersson C, Hellervik A and Lindgren K (2005) A spatial network explanation for a hierarchy of urban power laws, Physica A, 345(1-2): 227-244.

Andersson C, Frenken K and Hellervik A (2006) A complex network approach to urban growth, Environment and Planning A, 38(10): 1951-1964.

Barnett L, Di Paolo I and Bullock S (2007) Spatially embedded random networks. Physical Reviews E, 76(5): 056115.

Barabási AL and Albert R (1999) Emergence of scaling in random networks. Science, 286(5439): 509-512. 
Barber MJ, Fischer MM, Scherngell T (2011) The community structure of research and development cooperation in Europe: Evidence from a social network perspective, Geographical Analysis, 43(4): 415-432.

Barrat A, Barthélemy M and Vespignani A (2005) The effects of spatial constraints on the evolution of weighted complex networks. Journal of Statistical Mechanics: Theory and Experiment, $\mathrm{P} 05003$.

Barthélemy M (2003) Crossover from scale-free to spatial networks. Europhysics letters, 63: 915.

Barthélemy M (2010) Spatial networks. Physics Reports, 499:1-101.

Barthélemy M and Flammini A (2009) Co-evolution of density and topology in a simple model of city formation. Networks and Spatial Economics, 9(3): 401-425.

Batty M (2008) Cities as Complex Systems: Scaling, Interactions, Networks, Dynamics and Urban Morphologies. UCL Center for Spatial Analysis, paper 131 (63 pages).

Beauguitte L (2010) Looking for European Union in the Word-System: A multi-graph approach, Paper presented at the European Regional Science Association Conference, http://www-sre.wu.ac.at/ersa/ersaconfs/ersa10/ERSA2010finalpaper698.pdf

Béguin H and Thomas I (1997) The shape of the transportation network and the optimal location of facilities. How to measure the shape of a network? Cybergeo: European Journal of Geography, 26: http://cybergeo.revues.org/index2189.html (in French).

Berroir S, Cattan N, Guérois M, Paulus F and Vacchiani-Marcuzzo C (2012) Les systèmes urbains français, Synthèse DATAR, Travaux en Ligne $n^{\circ} 10$.

Blondel VD, Krings GM and Thomas I (2010) Regions and borders of mobile telephony in Belgium and around Brussels, Brussels Studies, 42, http://perso.uclouvain.be/vincent.blondel/publications/10B.pdf (Accessed June 2012).

Boccaletti S, Latora V, Moreno Y, Chavez M and Hwang DU (2006) Complex networks: Structure and dynamics. Physics Reports, 424(4-5) :175-308.

Bogart D (2009) Inter-modal network externalities and transport development: Evidence from roads, canals, and ports during the English Industrial Revolution, Networks and Spatial Economics, 9(3): 309-338.

Boguna M, Pastor-Satorras R, Diaz-Guilera A and Arenas A (2004) Models of social networks based on social distance attachment, Physical Review E, 70: 056122.

Borgatti SP, Mehra A, Brass DJ and Labianca G (2009) Network analysis in the social sciences. Science, 323(5916): 892-985.

Bosco FJ (2006) Actor-network theory, networks, and relational approaches in human geography, in Aitken S and Valentine G (Eds) Approaches to Human Geography, SAGE Publications, pp. 136-146.

Bretagnolle A (2009) Analyse morphodynamique du réseau des routes de poste en France (XVIe-XIXe siècles), in Bléton-Ruget A, Commerçon N and Vannier M (Eds) Réseaux en question : utopies, pratiques et prospective, Institut de recherche du Val de Saône-Maconnais, pp. 117-138.

Bretagnolle A and Pumain D (2010) Simulating urban networks through multiscalar spacetime dynamics: Europe and the United States, 17th-20th centuries. Urban Studies, 47(13): 2819-2839.

Buldyrev SV, Parshani R, Paul G, Stanley HE and Havlin S (2010) Catastrophic cascade of failures in interdependent networks, Nature, 464: 1025-1028.

Bullock S, Barnett L and Di Paolo E (2010) Spatial embedding and the structure of complex networks. Complexity, 16(2): 20-28.

Cardillo A, Scellato S, Latora V and Porta S (2005) Structural properties of planar graphs of urban street patterns. Physical Review E, 73(6): 066107. 
Caschili S and De Montis A (2013) Accessibility and complex network analysis of the U.S. commuting system, Cities, 30: 4-17.

Cattan N (1995a) Attractivity and internationalisation of major European cities: The example of air traffic. Urban studies, 32(2): 303-312.

Cattan, N. (1995b) Barrier effects: The case of air and rail flows, International Political Science Review, 16(3): 237-248.

Choi JH, Barnett JA and Chon BS (2006) Comparing world city networks: a network analysis of Internet backbone and air transport intercity linkages, Global Networks, 6(1): 81-99.

Cicéri MF, Marchand B and Rimbert S (1977) Introduction à l'analyse de l'espace, Paris: Masson.

Comin MN (2009) Networks of cities and networks of innovation in Europe: the structuring of the European system of cities through research networks dedicated to converging technologies, $\mathrm{PhD}$ dissertation in Geography, University of Paris I (724 pages).

Crossley N (2005) Review article: The New Social Physics and the Science of Small World Networks, Sociological Review, 53(2): 351-359.

Crossley N (2008) Small-world networks, complex systems and sociology. Sociology, 42(2): 261-277.

Dancoisne P (1984) Théorie des graphes et constitution du réseau ferré français, Unpublished $\mathrm{PhD}$ dissertation in Geography, Paris: Université Paris I.

Davis GF, Yoo M and Baker WE (2003) The small world of the American corporate elite, 1982-2001, Strategic Organization, 1(3): 301-326.

De Montis A, Chessa A, Caschili S, Campagna M and Deplano G (2010) Modeling commuting systems through a complex network analysis: A study of the Italian islands of Sardinia and Sicily. Journal of Transport and Land Use, 2(3/4): 39-55.

Devriendt L, Derudder B and Witlox F (2010) Conceptualizing digital and physical connectivity: The position of European cities in Internet backbone and air traffic flows. Telecommunications Policy, 34(8): 417-429.

Drevelle M (2013) Structure des navettes domicile-travail et polarités secondaires autour de Montpellier. Mappemonde, 110(2): http://mappemonde.mgm.fr/num35/articles/art12304.html Ducruet C (2013a) Network diversity and maritime flows. Journal of Transport Geography, 30: $77-88$.

Ducruet C (2013b) Mapping global urban interactions: Maritime flows and port hierarchies since the late nineteenth century, Globalisation and World Cities Research Bulletin, http://www.lboro.ac.uk/gawc/rb/rb429.html

Ducruet C, Rozenblat C, Zaidi F (2010) Ports in multi-level maritime networks: Evidence from the Atlantic (1996-2006), Journal of Transport Geography, 18(4): 508-518.

Ducruet C, Ietri D and Rozenblat C (2011a) Cities in worldwide air and sea flows: A multiple networks analysis. Cybergeo: European Journal of Geography, 528: http://cybergeo.revues.org/23603

Ducruet C, Lee SW, Song JM (2011b) Network position and throughput performance of seaports, in Notteboom TE (Ed) Current Issues in Shipping, Ports, and Logistics, ASP Publishers, Brussels, pp. 185-201.

Ducruet C and Lugo I (2013a) Cities and transport networks in shipping and logistics research. Asian Journal of Shipping and Logistics, 29(2): 145-166.

Ducruet C and Lugo I (2013b) Structure and dynamics of transport networks: concepts, models, and applications, in Rodrigue JP, Notteboom TE and Shaw J (eds.), The SAGE Handbook of Transport Studies, SAGE Publications Ltd., pp. 347-364.

Ducruet C and Notteboom TE (2012) The worldwide maritime network of container shipping: Spatial structure and regional dynamics, Global Networks, 12(3): 395-423. 
Ducruet C and Zaidi F (2012) Maritime constellations: A complex network approach to shipping and ports. Maritime Policy and Management, 39(2): 159-168. .

Dupuy G (ed.) (1988) Réseaux territoriaux. Caen, Paradigme (286 pages).

Erdös P and Rényi A (1959) On random graphs. Publicationes Mathematicae, 6: 290-297.

Eagle N, Macy M and Claxton R (2010) Network diversity and economic development. Science, 328(5981): 1029-1031.

Erath A, Löchl M, Axhausen KW (2009) Graph-theoretical analysis of the Swiss road and railway networks over time. Networks and Spatial Economics, 9(3): 379-400.

Evans AJ (2010) Complex spatial networks in application, Complexity, 16(2): 11-19.

Expert P, Evans TS, Blondel VD and Lambiotte R (2011) Uncovering space-independent communities in spatial networks, Proceedings of the National Academy of Sciences of the United States of America (PNAS), 108(19): 7663-7668.

Fleming L, King C and Juda A (2007) Small worlds and regional innovation. Organization Science, 18(6): 938-954.

Freeman L (2004) The Development of Social Network Analysis: A Study in the Sociology of Science. Vancouver: Empirical Press (218 pages).

Gabaix X and Ioannides Y (2004) The evolution of city size distributions, in Henderson JV and Thisse JF (eds) Handbook of Regional and Urban Economics, pp. 2341-2378.

Garrison WL (1960) Connectivity of the Interstate Highway System, Regional Science

Association, Papers and Proceedings, 6: 121-137.

Gastner MT and Newman MEJ (2006) Optimal design of spatial distribution networks. Physical Review E, 74(1): 16117.

Gattuso D and Miriello E (2005) Compared analysis of metro networks supported by graph theory. Networks and Spatial Economics, 5(4): 395-414.

Gleyze JF (2007) Making allowances for spatial and network effects when assessing indicators on infrastructure network nodes. Cybergeo: European Journal of Geography, 370, http://cybergeo.revues.org/index5532.html

Gleyze JF (2013) Topological clustering for geographical networks, in Rozenblat C and Melançon G (eds), Methods for Multilevel Analysis and Visualization of Geographical Networks, Springer, pp. 33-53.

Gorman SP, Schintler L, Kulkarni R and Stough R (2004) The revenge of distance: Vulnerability analysis of critical information infrastructure. Journal of Contingencies and Crisis Management, 12(2): 48-63.

Gorman SP and Kulkarni R (2004) Spatial small worlds: New geographic patterns for an information economy. Environment and Planning B, 31(2): 273-296.

Gorman SP, Patuelli R, Reggiani A, Nijkamp P, Kulkarni R and Haag G (2007) An application of complex network theory to German commuting patterns, in Friesz TL (Ed) Network Science, Nonlinear Science and Infrastructure Systems, Springer, New York, pp. 167-185.

Gosak M, Korosak D and Marhl M (2011) Topologically determined optimal stochastic resonance responses of spatially embedded networks, New Journal of Physics, 13: 013012.

Grabher G (2006) Trading routes, bypasses, and risky intersections: mapping the travels of 'networks' between economic sociology and economic geography. Progress in Human Geography, 30(2):1-27.

Grubesic TH, Matisziw TC and Zook MA (2008) Global airline networks and nodal regions. Geojournal, 71(1): 53-66.

Guimerà R and Amaral LAN (2005) Functional cartography of complex metabolic networks. Nature, 433(7028): 895-900. 
Guo D, Liu S and Jin H (2010) A graph-based approach to vehicle trajectory analysis, Journal of Location Based Services, 4(3-4): 183-199.

Haggett P and Chorley R (1969) Network Analysis in Geography. London: Edward Arnold (348 pages).

Hayashi Y and Matsukubo J (2006) Geographical effects on the path length and the robustness in complex networks, Physical Review E, 73: 066113.

Hillier B and Hanson J (1984) The Social Logic of Space, Cambridge: Cambridge University Press.

$\mathrm{Hu} \mathrm{Y}$ and Zhu D (2009) Empirical analysis of the worldwide maritime transportation network. Physica A, 388(101): 2061-2071.

Huang L, Yang L and Yang K (2005) Geographical effects on cascading breakdowns of scalefree networks. Physical Review E, 73(3): 036102.

Illenberger J, Nagel K and Flötteröd G (2013) The role of spatial interaction in social networks. Networks and Spatial Economics, 13(3): 255-282.

Jacobs W, Ducruet C and De Langen PW (2010) Integrating world cities into production networks: The case of port cities, Global Networks, 10(1): 92-113.

Jiang B and Claramunt C (2004) Topological analysis of urban streets. Environment and Planning B: Planning and Design, 31(1): 151-162.

Jin F, Wang C, Li X and Wang J (2010) China's regional transport dominance: Density, proximity, and accessibility, Journal of Geographical Sciences, 20(2): 295-309.

Kaiser M and Hilgetag CC (2004) Spatial growth of real-world networks. Physical Review E, 69: 036103.

Kansky KJ (1963) Structure of transportation networks: Relationship between network geometry and regional characteristics. Chicago: University of Chicago Press (155 pages).

Kurant M and Thiran P (2006) Extraction and analysis of traffic and topologies of transportation networks. Physical Review E, 74(3): 36114.

Lambert A, Bourqui R and Aubert D (2013) Graph visualization for geography, in Rozenblat $\mathrm{C}$ and Melançon G (eds), Methods for Multilevel Analysis and Visualization of Geographical Networks, Springer, pp. 81-102.

Lambiotte R, Blondel VD, de Kerchove C, Huens E, Prieur C, Smoreda Z and Van Dooren P (2008) Geographical dispersal of mobile communication networks, Physica A, 387(21): 53175325.

Lane D, van der Leeuw S, Pumain D and West G (2009) Complexity Perspectives in Innovation and Social Change, Methodos Series 7, Springer (492 pages).

Liefner I and Hennemann S (2011) Structural holes and new dimensions of distance: the spatial configuration of the scientific knowledge network of China's optical technology sector, Environment and Planning A, 43(4): 810-829.

Liu X, Derudder B and Gago Garcia C (2013) Exploring the co-evolution of the geographies of air transport aviation and corporate networks. Journal of Transport Geography, 30: 26-36.

Lugo I (2013) Spatial externalities approach to modelling the preferential attachment process in urban systems, Proceedings of the European Conference of Complex Systems 2012, Lecture Notes in Computer Science, Springer (forthcoming).

Mathis P (ed.) (2003) Graphes et réseaux. Modélisation multi-niveaux. Paris: Lavoisier (361 pages).

Matthiessen CW, Schwarz AW and Find S (2006) World cities of knowledge: research strength, networks and nodality, Journal of Knowledge Management, 10(5): 14-25.

Melançon G and Rozenblat C (2013) Structural analysis of networks, in Rozenblat C and Melançon G (eds), Methods for Multilevel Analysis and Visualization of Geographical Networks, Springer, pp. 69-80. 
Milgram S (1967) The Small World Problem. Psychology Today, 2: 60-67.

Miller HJ (1999) Potential Contributions of Spatial Analysis to Geographic Information Systems for Transportation (GIS-T), Geographical Analysis, 31(4): 373-399.

Newman MEJ (2000) Models of the Small World. Journal of Statistical Physics, 101(3-4): 819-841.

Newman MEJ (2010) Networks: An introduction. Oxford: Oxford University Press (784 pages).

Newman MEJ, Barabási AL and Watts D (eds) (2006) The Structure and Dynamics of Networks. Princeton: Princeton University Press (624 pages).

$\mathrm{Ng}$ AKY and Ducruet C (forthcoming) The changing tides of port geography (1950-2012). Progress in Human Geography.

Nystuen JD and Dacey MF (1961) A graph theory interpretation of nodal regions, Papers in Regional Science, 7(1): 29-42.

Opsahl T and Panzarasa P (2009) Clustering in weighted networks. Social Networks, 31(2): 155-163.

Parshani R., Rozenblat C., Ietri D., Ducruet C., Havlin S. (2010) Inter-similarity between coupled networks, Europhysics Letters, 92:68002.

Patuelli R, Reggiani A, Gorman S, Nijkamp P and Bade F (2007) Network analysis of commuting flows: A comparative static approach to German data. Networks and Spatial Economics, 7(4): 315-331.

Pflieger G and Rozenblat C (2010) Introduction. Urban networks and network theory: The city as the connector of multiple networks, Urban Studies, 47(13): 2723-2735.

Porta S, Crucitti P and Latora V (2006) The network analysis of urban streets: a primal approach, Environment and Planning B, 33(5): 705-725.

Porta S, Strano E, Iacoviello V, Messora R, Latora V, Cardillo A, Wang F and Scellato S (2009) Street centrality and densities of retail and services in Bologna, Italy, Environment and Planning B, 36: 450-465.

Porta S, Latora V, Wang F, Rueda S, Strano E, Scellato S, Cardillo A, Belli E, Cardenas F, Cormenzana B and Latora L (2012) Street centrality and the location of economic activities in Barcelona, Urban Studies, 49(7): 1471-1488.

Produit T, Lachance-Bernard N, Strano E, Porta S and Joost S (2010) A network based Kernel density estimator applied to Barcelona economic activities, Lecture Notes in Computer Science, 6016: 32-45.

Pumain D (1982) La dynamique des villes, Paris: Economica.

Radil SM, Flint C and Tita GE (2010) Spatializing social networks: Using social network analysis to investigate geographies of gang rivalry, territoriality, and violence in Los Angeles. Annals of the Association of American Geographers, 100(2): 307-326.

Reggiani A (2011) Accessibility and resilience in complex networks, Paper presented at West Virginia University, 28 April 2011.

Reggiani A, Bucci P, Russo G, Haas A and Nijkamp P (2011) Regional labour markets and job accessibility in City Network systems in Germany, Journal of Transport Geography, 19(4): 528-536.

Reggiani A, Bucci P, Russo G (2011) Accessibility and network structures in the German commuting. Networks and Spatial Economics, 11(4): 621-641.

Reggiani A and Vinciguerra S (2011) Network connectivity models: An overview and empirical applications, in Friesz $\mathrm{T}$ (ed), Network Science, Nonlinear Science and Infrastructure Systems, Springer, pp. 147-165.

Robson BT (1973) Urban growth, an Approach, London: Methuen. 
Rosato V, Issacharoff L, Tiriticco F, Meloni S, De Porcellinis S and Setola R (2008) Modelling interdependent infrastructures using interacting dynamical models, International Journal of Critical Infrastructures, 4(1-2): 63-79.

Rozenblat C and Pumain D (1993) The location of multinational firms in the European urban system. Urban studies, 30(10): 1691-1709.

Rozenblat C and Mélançon G (2007) A small world perspective on urban systems. Handbook of Theoretical and Quantitative Geography, Lausanne: Univ. of Lausanne Ed., pp. 431-467.

Rozenblat C (2010) Opening the black box of agglomeration economies for measuring cities' competitiveness through international firm networks, Urban Studies, 74(13): 2841-2865.

Rozenblat C, Melançon G, Bourqui R and Auber D (2013) Comparing multilevel clustering methods on weighted graphs: The case of worldwide air passenger traffic 2000-2004, in Rozenblat C and Melançon G (eds), Methods for Multilevel Analysis and Visualization of Geographical Networks, Springer, pp. 141-154.

Schintler LA, Kulkarni R, Gorman S and Stough R (2007) Using raster-based GIS and graph theory to analyze complex networks, Networks and Spatial Economics, 7(4): 301-313.

Scott DW, Novak D, Aultman-Hall M and Guo F (2005) Network robustness index: A new method for identifying critical links and evaluating the performance of transportation networks. Working Paper 9, Centre for Spatial Analysis, Hamilton, Canada: http://www.science.mcmaster.ca/cspa/papers/CSpA\%20WP\%20009.pdf

Stoneham AKM (1977) The small-world problem in a spatial context. Environment and Planning A, 9(2): 185-195.

Strano E, Nicosia V, Latora V, Porta S, Barthélemy M (2012) Elementary processes governing the evolution of road networks, Scientific Reports, 2: 296.

Sui DZ (2004) Tobler's first law of geography: A big idea for a small world? Annals of the Association of American Geographers, 94(2): 269-277.

Taaffe EJ, Morrill RL and Gould PR (1963) Transport expansion in underdeveloped countries: A comparative analysis, Geographical Review, 4: 503-529.

Ter Wal ALJ and Boschma RA (2009) Applying social network analysis in economic geography: Framing some key analytic issues. The Annals of Regional Science, 43(3): 739756.

Thomas I (2002) Transportation Networks and the Optimal Location of Human Activities: A Numerical Geography Approach, Edward Elgar Publishing, Northampton MA.

Tissandier P, Phan Quang TT and Archambault D (2013) Defining polycentric urban areas through commuting cohesion in France, in Rozenblat C and Melançon G (eds), Methods for Multilevel Analysis and Visualization of Geographical Networks, Springer, pp. 189-206.

Tobler W (1970) A computer movie simulating urban growth in the Detroit region, Economic Geography, 46(2): 234-240.

Tranos E (2011) The topology and the emerging urban geographies of the Internet backbone and aviation networks in Europe: A comparative study, Environment and Planning A, 43: 378-392.

Vespignani A (2010) Complex networks: The fragility of interdependency, Nature, 464: 984985.

Vinciguerra S, Frenken K and Valente M (2010) The geography of Internet infrastructure: an evolutionary simulation approach based on preferential attachment. Urban Studies, 47(9): 1969-1984.

Vitali S and Battiston S (2011) Geography versus topology in the European Ownership Network, New Journal of Physics, 13: 063021. 
Wang J, Jin F, Mo H and Wang F (2009) Spatiotemporal evolution of China's railway network in the 20th century: An accessibility approach. Transportation Research Part A, 43(8): 765-778.

Wang J, Mo H, Wang F and Jin F (2011) Exploring the network structure and nodal centrality of China's air transport network: A complex network approach, Journal of Transport Geography, 19(4): 712-721.

Wasserman S and Faust K (1994) Social Network Analysis: Methods and Applications. Cambridge: Cambridge University Press (857 pages).

Waters N (2006) Network and Nodal Indices. Measures of Complexity and Redundancy: A Review, in Reggiani A and Nijkamp P (eds), Spatial dynamics, networks and modelling, Northampton: Edward Elgar Publishing, pp. 13-33.

Watts DJ (2003) Six degrees. The Science of a Connected Age. New-York: W.W. Norton \& Company (368 pages).

Wong LH, Pattison P and Robins G (2006) A spatial model for social networks, Physica A, 360: 99-120.

Xie F and Levinson D (2007) Measuring the structure of road networks, Geographical Analysis, 39: 336-356.

Xie F and Levinson D (2009) Modeling the growth of transportation networks: A comprehensive review, Networks and Spatial Economics, 9(3): 291-307.

Zaidi F (2011) Analysis, Structure and Organization of Complex Networks. Saarbrucken: Lambert Academic Publishing (156 pages).

Zhang PC, Peeta S and Friesz T (2005) Dynamic game theoretic model of multi-layer infrastructure networks, Networks and Spatial Economics, 5: 147-178. 


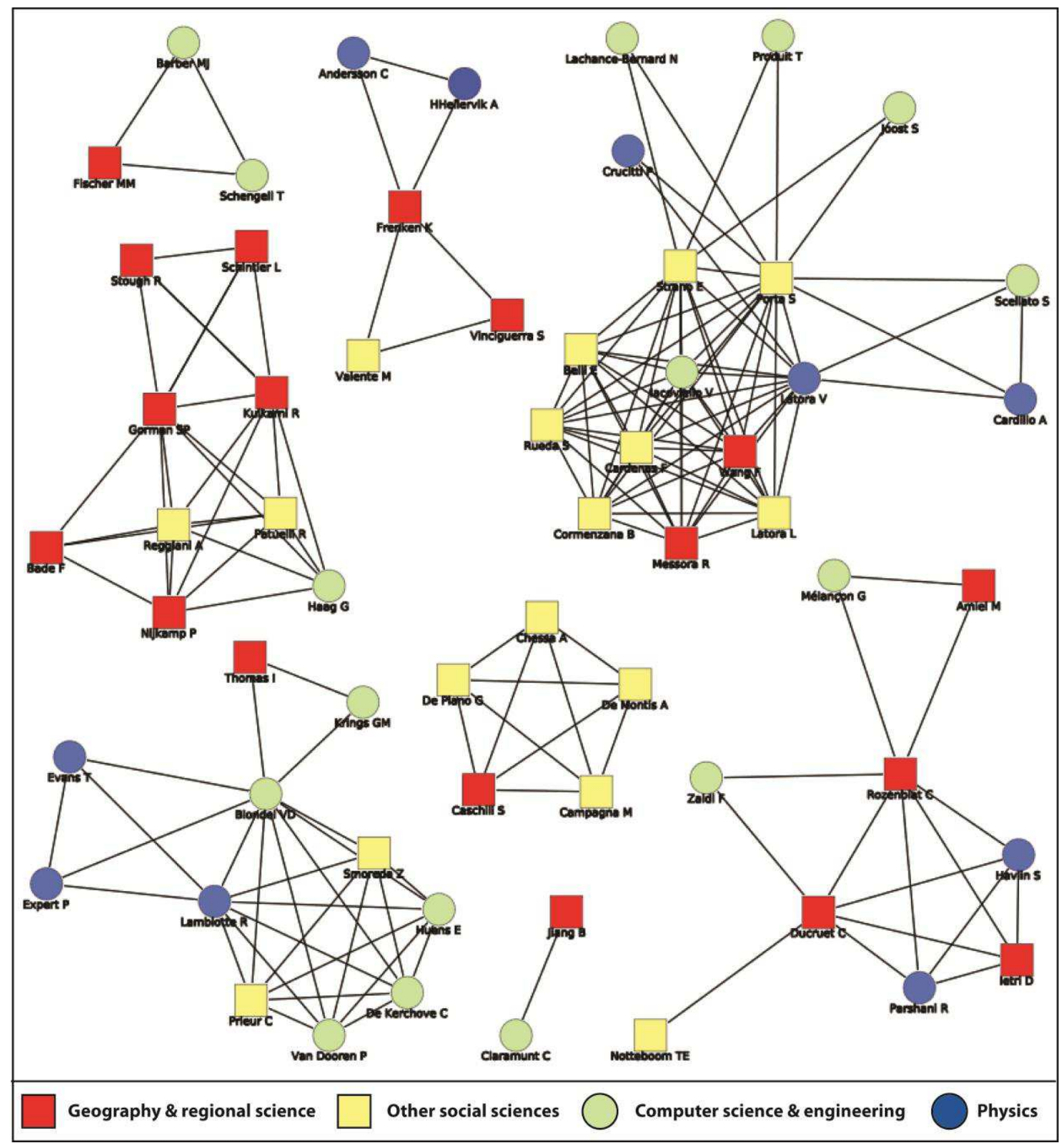

Figure 1: Graph of collaborations in the field of complex networks research including geographers and regional scientists 